\title{
PROCESSO PENAL E MEDIDA DE SEGURANÇA: UM ESTUDO DA DESINTERNAÇÃO PROGRESSIVA COMO INSTRUMENTO DE REINSERÇÃO SOCIAL
}

\section{CRIMINAL PROCEDURE AND SECURITY MEASURE: A STUDY OF PROGRESSIVE SUSPENSION OF INTERNMENT AS SOCIAL REINTEGRATION INSTRUMENT}

\author{
${ }^{1}$ Gilberto Giacoia \\ ${ }^{2}$ Letícia Gabriella Almeida
}

\section{RESUMO:}

Na perspectiva de efetivação do princípio da dignidade da pessoa humana, o texto, a partir da análise dogmático-conceitual da culpabilidade penal, periculosidade do inimputável e medidas de segurança, enfrenta a problemática da limitação de sua execução pelo processo de desinternação progressiva como instrumento de reinserção social, fundada em uma hermenêutica constitucional, sob influência da chamada reforma psiquiátrica.

PALAVRAS-CHAVE: Dignidade da pessoa humana; periculosidade; medidas de segurança; desinternação progressiva; reforma psiquiátrica.

\begin{abstract}
:
With a view of realization of the principle of human dignity, the text, from the dogmatic and conceptual analysis of criminal culpability, dangerousness of "not imputable" and security measures, faces the problematic of the limitation of its implementation by the progressive suspension of internment process as a tool for social reintegration, founded on a constitutional hermeneutics, under the influence of so-called psychiatric reform.
\end{abstract}

KEYWORDS: Principle of human dignity; dangerousness; security measures; progressive suspension of internment; psychiatric reform.

\footnotetext{
${ }^{1}$ Procurador de Justiça, ex-procurador-geral de Justiça do Paraná, doutor em Direito pela Universidade de São Paulo, USP - SP, (Brasil) e pós-doutor pelas Universidades de Coimbra, UC - Coimbra, (Portugal) e Universidade de Barcelona, (Espanha). E-mail: giacoia@brturbo.com.br

${ }^{2}$ Mestranda em Ciência Jurídica pela Universidade Estadual do Norte do Paraná, UENP - PR, (Brasil).E-mail: leticiagabriellaa@hotmail.com
} 


\section{INTRODUÇÃO}

Como se sabe, a questão da inimputabilidade, na teoria geral do delito e da pena, sempre esteve na ordem do dia, por envolver temática que se conecta, diretamente, com uma das funções precípuas do Estado, a justificar sua existência na defesa da sociedade, concepção dentro da qual se desenvolve e se fundamenta o próprio sistema sancionador. Com efeito, para facilitar e regulamentar a convivência dos homens em sociedade, impõe-se o atuar de um sistema que assegure mecanismos de controle social, colocados a serviço da tutela de determinados bens jurídicos, reputados relevantes à sobrevivência da organização dos homens em comunidade.

Nesse contexto, o esforço legitimador desse mesmo sistema sancionador sempre trabalhou bem com o quadro de imputabilidade, porquanto a justificação da pena, associada à função de defesa social e de resposta a quem, com consciência e vontade livres, optou pelo desrespeito a tais valores, independe de construções dogmáticas mais complexas.

No entanto, em diferentes épocas, o tratamento dispensado aos inimputáveis, no âmbito do Direito Penal, nunca mereceu solução tão tranquila, ora atuando, conceitualmente, a compreensão de periculosidade social, ora de periculosidade criminal mais limitada, porque fundada na incapacidade penal do agente inimputável.

Como tal quadro em parte persiste, porquanto mesmo depois do movimento que inspirou a denominada reforma psiquiátrica, há quem não se preocupe com a incidência indeterminada dessas medidas, porque as entende vinculadas à persistência de periculosidade do agente, a presente pesquisa propõe-se a defender o instituto da desinternação progressiva como meio de promoção da ressocialização e da defesa da dignidade do internado.

Nesse propósito, inicia com uma primeira parte conceitual e procedimental a respeito da culpabilidade e da periculosidade, abordando a evolução de seus respectivos tratamentos dogmáticos na ordem jurídica pátria, bem como a forma de apuração, no que diz respeito aos critérios de inimputabilidade adotados pelo Código Penal, em específico por meio do incidente de insanidade mental do acusado.

Na segunda parte, cuida-se da aplicação das medidas de segurança, suas modalidades e suas formas de incidência e aplicação, ainda sem fugir de uma visão histórico-evolutiva mesmo que mais restrita à legislação brasileira.

Já na terceira e última parte, concentra-se, propriamente, no objeto da investigação, que é o tratamento da desinternação progressiva, na linha de inspiração da reforma 
psiquiátrica, buscando justificá-la com base no princípio da dignidade da pessoa humana e na exigência, decorrente de matriz constitucional, de limitação das medidas penais, sem afastamento do foco, contudo, da defesa social, vez que sustentada no propósito comum de reinserção social do internado.

Em paralelo à concentrada crítica na filosofia tradicional do tratamento manicomial, conclui-se que a desinternação progressiva pode ser, assim, um instrumento eficaz na efetivação dos princípios constitucionais e de inclusão social do sujeito inimputável, e que por isso mesmo deve compor a lógica de organização do Sistema de Saúde Mental, de modo a integrá-la.

\section{ASPECTOS PROCESSUAIS: CULPABILIDADE E PERICULOSIDADE}

Sob a ótica da teoria geral do crime, uma vez caracterizado um fato como típico e ilícito, resta à culpabilidade comprovar a incidência de seus elementos e revelar o ilícito penal. Luiz Regis Prado (2011, p. 469), ao levantar o assunto, evidencia a possibilidade de existir uma ação típica e ilícita inculpável, mas não uma ação culpável que não seja típica e ilícita. Para o autor, a culpabilidade está sempre adstrita ao fato, sendo que cada nível subsequente do delito contém o antecedente como pressuposto.

Por isso mesmo, tem-se associado conceitualmente - pela utilização que o Estado faz do Direito Penal (pretensamente para facilitar e regulamentar a convivência em sociedade, não obstante a existência de outros meios de controle social) -, Estado, pena e culpabilidade, dada sua complementariedade e consequente dinâmica, de modo a se aperfeiçoar, progressivamente, o Direito Penal à medida em que se evolui a forma de Estado e, assim, por estar vinculada uma teoria da pena, destinada à compreensão de sua natureza, função e finalidade, ao respectivo conceito dogmático de culpabilidade que se adote. Daí já se ter afirmado que "pelo aperfeiçoamento da teoria de culpabilidade, mede-se o progresso do Direito Penal" (Von Liszt). A despeito dessa associação que mais conduziria a culpabilidade como fundamento da pena, o certo é que tipicidade, antijuridicidade e culpabilidade são predicados de um substantivo que é a conduta humana definida como crime, como anota Cezar Roberto Bitencourt (2000, p. 273).

Destarte, a culpabilidade complementa o fato típico e ilícito indicando fundamento e limite para a pena a ser aplicada, atuando de forma a efetivar os princípios da culpabilidade e 
da dignidade da pessoa humana. Nesse sentido Pierangeli e Zaffaroni (2011, p. 521) conceituam a culpabilidade como reprovabilidade do injusto ao autor. Pauta-se na ideia do injusto como fato típico e ilícito, tratando a realização da conduta culpável porque não se motivou na norma, sendo-lhe exigível, nas circunstâncias em que agiu, que nela se motivasse.

Insta salientar que a concepção atual dos elementos da culpabilidade reproduz os ideais da teoria normativa pura, influenciada pela teoria finalista da ação. Nesse sentido, a culpabilidade é constituída pela potencial consciência da ilicitude, pela exigibilidade de conduta diversa e pela imputabilidade.

A potencial consciência da ilicitude, retirada do dolo para constituir elemento autônomo, é a possibilidade de conhecimento da antijuridicidade do fato, isto é, para que uma ação contrária ao Direito possa ser reprovada ao autor, será necessário que o mesmo conheça ou possa conhecer as circunstâncias que pertencem ao tipo e à ilicitude (BITENCOURT, 2009. p. 375).

A exigibilidade de conduta diversa consiste na expectativa social de um comportamento diferente daquele que foi adotado pelo autor. É a possibilidade que tinha o agente de, no momento da ação ou da omissão, agir de acordo com o direito, considerando-se a sua particular condição de pessoa humana.

Por fim, a imputabilidade se refere à capacidade mental do agente de compreender o caráter ilícito do fato praticado e de determinar-se de acordo com isso. Segmenta-se em dois elementos: um intelectual, determinando a compreensão ao caráter ilícito do fato; e um volitivo, controlando e conduzindo sua conduta no sentido do entendimento obtido.

Neste contexto, e com ênfase no elemento mais relevante para o presente estudo, resta estruturado um binômio necessário para formação das condições pessoais do imputável, formado pela maturidade e sanidade mental (NUCCI, 2011, p. 306). A maturidade, de acordo com o Código Penal, é definida pelo critério cronológico, iniciando-se aos 18 anos. No tocante à higidez mental, três são os sistemas observados: biológico, psicológico e biopsicológico. Em síntese (BITENCOURT, 2009. p. 379).

O sistema biológico condiciona a responsabilidade à saúde mental, à normalidade da mente. Se o agente é portador de uma enfermidade ou grave deficiência mental, deve ser declarado irresponsável, sem necessidade de ulterior indagação psicológica. $\mathrm{O}$ método psicológico não indaga se há uma perturbação mental mórbida: declara a irresponsabilidade se, ao tempo do crime, estava abolida no agente, seja qual for a causa, a faculdade de apreciar a criminalidade do fato (momento intelectual) e de determinar-se de acordo com essa apreciação (momento volitivo). Finalmente, $o$ método biopsicológico é a reunião dos dois primeiros: a responsabilidade só é 
excluída, se o agente, em razão de enfermidade ou retardamento mental, era, ao tempo da ação, incapaz de entendimento ético-jurídico e autodeterminação.

O artigo 26 do Código Penal evidencia a adoção do sistema biopsicológico, declarando isento de pena o agente que, por doença mental ou desenvolvimento mental incompleto ou retardado, era, ao tempo da ação ou omissão, inteiramente incapaz de entender o caráter ilícito do fato ou de determinar-se de acordo com esse entendimento.

Por doença mental compreende-se uma perturbação mental ou psíquica de qualquer ordem, capaz de eliminar ou afetar a capacidade de entendimento do agente em relação ao caráter criminoso do fato ou de comandar sua vontade de acordo com esse entendimento. Para Nucci (2011. p. 308), o conceito abordado pelo Código deve ser analisado em sentido lato, abrangendo doenças de origem patológica e toxicológica, tais como a epilepsia, a histeria, neurastenia, psicose maníaco-depressiva, melancolia, paranoia, alcoolismo, senilidade, entre outras. Alguns estudiosos ainda interpretam as expressões da lei em correspondência aos principais quadros psiquiátricos, atribuindo à doença mental as psicoses e demências graves e moderadas; à perturbação da saúde mental, as demências iniciais, as neuroses, parafilias e transtornos de personalidade; e, ao desenvolvimento mental retardado, as oligofrenias em qualquer grau que se manifestem (TABORDA; ABDALLA-FILHO; CHALUB. 2012. p. 146 $-147)$.

O desenvolvimento mental incompleto, por sua vez, é o desenvolvimento que ainda não se concluiu, em razão da recente idade cronológica do agente ou à sua falta de convivência em sociedade. O artigo 228 da Constituição Federal e o artigo 27 do Código Penal dispõem que os menores de dezoito anos são penalmente inimputáveis, ficando sujeitos às normas estabelecidas na legislação especial (Estatuto da Criança e do Adolescente - Lei 8.069/90). O termo abrange, também, os surdos-mudos e os silvícolas inadaptados, os quais se sujeitam ao sistema biopsicológico e só serão considerados inimputáveis após análise do caso concreto (BITENCOURT, 2009, p. 383 - 384).

Já o desenvolvimento mental retardado revela-se quando a capacidade não corresponde às expectativas para aquele momento da vida, o que pode resultar em inimputabilidade ou semi-imputabilidade, a depender da perícia médica realizada. É o caso dos oligofrênicos, pessoas com reduzidíssimo coeficiente intelectual que ficam impossibilitadas de efetuar uma correta avaliação da situação de fato que se lhes apresenta, não tendo, por conseguinte, condições de entender o crime que cometeram. 
Esclarecidas tais premissas, a incidência das hipóteses supramencionadas no caso concreto implica em inimputabilidade e consequente absolvição do agente, conforme preleciona o inciso VI do artigo 386 do Código de Processo Penal. Transcreve-se:

Art. 386. O juiz absolverá o réu, mencionando a causa na parte dispositiva, desde que reconheça: [...] VI - existirem circunstâncias que excluam o crime ou isentem o réu de pena (arts. 20,21, 22, 23, 26 e $§ 1^{\text {o }}$ do art. 28, todos do Código Penal), ou mesmo se houver fundada dúvida sobre sua existência;

Insta salientar, no entanto, que a absolvição nos termos do artigo transcrito nem sempre acarretará em medida de segurança, o que será verificado a seguir.

\subsection{A periculosidade como fundamento da medida de segurança}

Conforme exposto anteriormente, a culpabilidade integra um dos elementos do crime, sendo indispensável para sua formação. Uma vez afastada, portanto, o delito é desconstituído e não é possível a aplicação de pena.

Por outro lado, a medida de segurança encontra fundamento na periculosidade/perigosidade do agente, que substitui o elemento subjetivo do tipo (dolo ou culpa) e supre a ausência de culpabilidade do inimputável (CARDOSO, 2012. p. 48.)

Assim, enquanto a culpabilidade é observada mediante um juízo passado, a periculosidade refere-se a um juízo futuro. Não diz respeito à conduta típica já praticada, mas a tendência de que o agente volte a delinquir, em razão da sua perturbação mental, que impossibilita o entendimento ou o controle a certos impulsos delitivos.

Em uma análise terminológica, é possível observar que o momento histórico e o desenvolvimento da sociedade são fatos essenciais para a formação de um conceito acerca da periculosidade. Ao longo do tempo, o termo compreendeu duas espécies: social e criminal.

Influenciada pela Escola Positiva italiana (século XIX), a periculosidade social tende a tornar dispensável a prática de um crime na aplicação da medida de segurança, supervalorizando a defesa social (CARDOSO, 2009, p. 49). Sob essa ótica, a "mera possibilidade de que um sujeito venha a cometer fatos socialmente danosos à coletividade, colocando em risco a tranquilidade pública” (FERRARI, 2001, p. 154) já torna possível a segregação social.

Neste contexto, são eleitos alguns "cidadãos perigosos", tais como os mendigos, as prostitutas, os toxicômanos e os enfermos mentais, e a eles são impostos o tratamento e a 
segregação, como forma de prevenir a coletividade de possíveis inconveniências. A prática tornou-se comum com os Estados totalitários, mormente contra os denominados inimigos políticos da nação (FERRARI, 2001, p. 155).

Com a reafirmação do Estado Democrático de Direito, restou necessária a substituição da periculosidade social pela criminal, haja vista a adoção de princípios incompatíveis com a prática do isolamento por discriminação.

A periculosidade criminal pauta-se na probabilidade de reincidência, e não em mera possibilidade. Diferenciam-se os termos no sentido de que, este, traduz uma incerteza dos acontecimentos futuros, enquanto aquele indica um "juízo de certeza sobre a constância da frequência desses mesmos acontecimentos incertos" (FERRARI, 2001, p. 156).

A prática de um ato delituoso, portanto, não incide diretamente na aplicação da medida de segurança, que fica condicionada à probabilidade de reiteração criminal. Nesse sentido é a redação do Código Penal brasileiro, que evidencia a periculosidade como fundamento da referida sanção penal, integrando um de seus pressupostos, que serão abordados em momento oportuno. Acerca do assunto (CARDOSO. 2012. p. 50):

\footnotetext{
Após a constatação de incidência do art. 26 do CP, isentando-se de pena o agente acometido por doença mental ou desenvolvimento mental incompleto ou retardado, não é imediata a aplicação do art. 97 do $\mathrm{CP}$, não podendo o juiz determinar a internação ou submissão do inimputável a tratamento ambulatorial sem, antes, verificar cuidadosamente a probabilidade de o mesmo tornar a delinqüir.
}

Enfim, ressalta-se que a constatação da periculosidade exige uma série de formalidades, haja vista sua repercussão no processo de apuração do fato e na execução penal. Em razão disso, instituiu-se instrumento apropriado para averiguação da periculosidade do autor, denominado de incidente de insanidade mental, tratado a seguir.

\subsection{A constatação da periculosidade por meio do incidente de insanidade mental}

O incidente de insanidade mental do acusado encontra respaldo legal no Capítulo VIII do Código de Processo Penal brasileiro, o qual indica suas hipóteses de instauração, o procedimento a ser seguido e as consequências da eventual constatação de inimputabilidade.

Dispõe o referido diploma processual, em seu artigo 149, caput, que havendo dúvidas acerca da integridade mental do acusado, caberá ao juiz ordenar, de ofício ou a 
requerimento do Ministério Público, do defensor, do curador, do ascendente, descendente, irmão ou cônjuge do acusado, sua submissão a este exame médico-psiquiátrico.

Eugênio Pacelli (2015, p. 324) menciona, todavia, que o rol de legitimados não é taxativo, uma vez que a apuração da insanidade mental do acusado é de interesse público. Dessa forma, qualquer pessoa interessada poderá provocar a instauração do respectivo incidente.

O exame deve ser autuado em apartado para depois ser apensado aos autos principais, devendo ser sempre específico para os fatos em análise. Nesse sentido aduz Vicente Greco Filho (2010. p. 182, grifo do autor):

\footnotetext{
O exame será sempre específico para os fatos relatados no inquérito ou no processo, e não pode ser substituído por interdição civil ou exame de insanidade realizado em razão de outro fato. Isto porque, em virtude do sistema biopsicológico sobre a inimputabilidade acolhido pelo Código Penal, os peritos devem responder se à época do fato o acusado era, ou não, capaz de entender o caráter criminoso do fato e de determinar-se segundo esse entendimento. Logo, não pode haver aproveitamento de outro exame referente a outro fato.
}

Ainda, destaca-se que o incidente poderá ser requerido em qualquer fase da persecução penal.

Tratando-se de dúvidas provenientes do inquérito policial, poderá a respectiva autoridade representar ao magistrado, pugnando pela realização do exame de insanidade mental nos termos do artigo $149 \S 1^{\circ}$ do Código de Processo Penal.

Aqui, em contraponto à interpretação meramente literal do dispositivo citado, entende-se que a solicitação do exame fica sujeita a uma análise discricionária do juiz de direito, o qual observará a existência real de suspeita ou desconfiança em relação à higidez mental do acusado. Determinada a perícia psiquiátrica, o inquérito policial terá seu curso regular, excluindo-se apenas os atos que dependam de presença ou colaboração do indiciado. Concomitantemente, tramitará o incidente perante o juízo criminal natural da futura ação, sendo nomeado um curador ao indiciado e formulados quesitos por ele, pelo Ministério público e pelo juiz da causa, a serem respondidos pelo perito judicial (PONTE, 2012, p. 62).

Findo o inquérito, os autos serão remetidos ao Ministério Público. Comprovada por perícia a insanidade mental do acusado, há quem sustente que poderá o promotor pugnar pela absolvição imprópria do denunciado, nos termos do artigo 386, VI, e parágrafo único, III, do Código de Processo Penal ou, em se tratando de semi-imputável, pela procedência da ação, com a imposição de pena reduzida ou medida de segurança. Em homenagem ao princípio do 
contraditório, porém, preferível - e até impositivo - optar o representante do Parquet pelo oferecimento da denúncia, quando então o processo terá tramitação normal. Uma vez recebida a peça vestibular, o curador do acusado será citado formalmente para oferecer a defesa prévia e atuar nas demais fases do processo judicial.

Já em se tratando de suspeita de inimputabilidade no curso de processo regular, o incidente será ordenado de ofício pelo juiz ou por requerimento das pessoas já elencadas, sendo nomeado um curador ao acusado. Os autos principais permanecem suspensos - sem a suspensão da prescrição - até a conclusão do incidente, que se submete à elaboração de um laudo pericial, sujeito a formulação de quesitos pelo Ministério Público, pelo juiz da causa e, em razão da incidência do contraditório não observado no inquérito policial, também pelo acusado (PONTE, 2012, p. 62).

Em consonância ao disposto no artigo 150 § $1^{\circ}$ do diploma processual já mencionado, o laudo terá o prazo de 45 dias para elaboração e conclusão, podendo ser homologado ou impugnado pelo magistrado. No primeiro caso, reconhecida a insanidade mental pelo juiz, esse deverá nomear curador ao réu, quando ainda não nomeado. Caso o laudo seja impugnado, o magistrado deverá apresentar argumentos consistentes e determinar a feitura de um novo exame. Após o laudo, o incidente será apenso ao processo principal.

Encerrada a instrução criminal, o juiz sentencia a causa. Se reconhecida a inimputabilidade, o juiz absolverá impropriamente o acusado, aplicando a medida de segurança adequada. Constatada a semi-imputabilidade, poderá o juiz optar pela imposição da pena reduzida ou, excepcionalmente, por medida de segurança, desde que represente uma possibilidade mais eficaz de tratamento ou recuperação. Observada a imputabilidade do agente, o juiz procederá com a imposição de pena.

Ainda neste contexto, duas situações merecem destaque.

Inicialmente, o artigo 152 do Código de Processo Penal prevê a hipótese de doença mental superveniente à infração. Nestes casos, sem prejuízo das correntes doutrinárias que afirmam ser o dispositivo inconstitucional, o feito deverá ser suspenso até que o acusado se restabeleça.

Em segundo lugar, ressalta-se a hipótese de superveniência da doença mental, ou seja, quando ela surge na fase de execução da pena. Aqui, o artigo 183 da Lei de Execução Penal dispõe que o Juiz, de ofício, a requerimento do Ministério Público, da Defensoria 
Pública ou da autoridade administrativa, poderá determinar a substituição da pena por medida de segurança.

Delimitados os diversos procedimentos para constatação da insanidade mental, constata-se, em síntese, que observada a inimputabilidade, ainda que o sujeito seja capaz de cometer um injusto penal, não merece ser socialmente reprovado, por ausência de capacidade de entendimento do ilícito ou de determinação de agir conforme esse entendimento. Tratandose de semi-imputabilidade, o agente preenche os requisitos para sofrer juízo de culpabilidade, haja vista o entendimento parcial do injusto cometido. No primeiro caso, aplicar-se-á medida de segurança. Em relação aos semi-imputáveis, contudo, haverá condenação, recebendo o condenado pena reduzida, salvo se a medida de segurança mostrar-se mais eficaz para sua recuperação.

\section{A APLICAÇÃO DE MEDIDA DE SEGURANÇA}

A primeira menção ao termo "medida de segurança" estava intimamente ligada à ideia de periculosidade social, abordada no tópico anterior. Segregavam-se os indivíduos considerados perigosos, mantendo o isolamento como forma de proteger a sociedade, de garantir a ordem.

Ainda nesse contexto, o final do século XIX evidenciou a chamada "crise da pena", revelando a ineficácia da intimidação e do castigo frente aos criminosos habitualmente reincidentes e menores de idade.

Essa necessidade de defesa social associada à crise da pena ensejou uma discussão sobre a importância de fundamentos preventivos na sanção penal, dividindo os estudiosos em duas correntes.

Para a primeira, a pena deveria ser mantida e, sob a premissa de que o agente precisa de tratamento, teria seu fim retributivo convertido em preventivo.

A segunda corrente, por sua vez, defende a manutenção do caráter retributivo da pena, e a criação paralela de uma nova espécie de sanção penal, esta de cunho eminentemente preventivo. Tal modalidade obteve apoio ideológico da Escola positivista italiana e foi impulsionada pelo movimento da Defesa Social e pelas ideias da pena-fim de Von Listz, razão pela qual a "medida de segurança, embebida dos princípios da defesa social, do determinismo, da periculosidade e do utilitarismo foi finalmente positivada no Anteprojeto do Código Penal Suíço de 1893, de autoria de Karl Stoos” (CARDOSO, 202, p. 36). 
O referido texto previa, em seu artigo 40, que a medida de internamento em instituições específicas seria imposta nos casos em que a pena não fosse eficaz. Haveria, portanto, uma substituição da pena pela medida de segurança (FERRARI, 2001, p. 31).

A sistematização dessa nova modalidade de sanção penal no Anteprojeto do Código Penal Suiço, em 1893, foi seguida por diversos projetos, códigos e leis criminais ao redor do mundo.

No Brasil, em que pese a medida de tratamento já fosse disciplinada sob a denominação de pena, foi o Decreto $n^{\circ}$ 1.132, de 22 de dezembro de 1903 que fez menção, pela primeira vez, ao termo. Dispunha o texto legal em seu artigo $1^{\circ}$ : “O individuo que, por molestia mental, congenita ou adquirida, comprometter a ordem publica ou a segurança das pessoas, será recolhido a um estabelecimento de alienados” (BRASIL, 1903).

Em 1913, o Projeto do Código Penal de Galindo Siqueira também previa a segregação do alienado em manicômios. Ressalta-se que foi incorporada nesse projeto a imposição de uma pena complementar ao reincidente perigoso, cuja duração era três vezes superior à comum, não ultrapassando o limite de 15 anos em qualquer caso.

A medida de tratamento veio a ser discutida novamente em 1927, com o projeto de Vergílio de Sá Pereira. O projeto, contudo, não prosperou.

Finalmente, a promulgação do Código Penal de 1940 instituiu, de fato e de direito, a medida de segurança no Brasil. A codificação adotou o sistemado duplo binário (vide item 2.1.2), estabelecendo que, observada a periculosidade do agente, imputável ou não, a pena e a medida de segurança poderiam ser aplicadas conjunta e sucessivamente, cessando apenas com a cura total do indivíduo.

O Código Penal de 1969 manteve boa parte dos dispositivos já vigentes. Ainda assim, trouxe importantes inovações no âmbito da inimputabilidade e da execução penal, entre as quais se destaca a necessidade do julgador em considerar o indivíduo imputável ou inimputável, aplicando, para cada um, a sanção penal ou a medida de segurança, isoladamente. Também foi conferida maior importância ao semi-imputável, ficando a critério do juiz a aplicação da medida de segurança ou de pena diminuída.

Apesar das importantes mudanças, o Código de 1969 sofreu diversas prorrogações quanto à sua vigência e, em 1975, finalmente, foi revogado, sem nunca ter, em efetivo, entrado em vigor. Manteve-se integralmente a legislação penal de 1940, preservando o sistema duplo binário e a presunção da periculosidade. 
Tais ideias, contudo, já destoavam do entendimento criminal brasileiro, razão pela qual a medida de segurança se tornou um dos temas mais relevantes da comissão constituída em 1981, responsável por importantes alterações no Código Penal (FERRARI, 2001, p. 39).

Neste contexto, a Lei no 7.209 de 1984 instituiu a reforma da Parte Geral do Código, que definiu padrões vigentes até hoje.

Adotou-se o sistema vicariante, determinando que as medidas de segurança seriam atribuídas apenas aos inimputáveis e, excepcionalmente, aos semi-imputáveis, nos termos do artigo 26 do referido diploma legal e, neste caso, em sustituição à pena.

Além disso, a reforma impôs o princípio da legalidade de forma absoluta, ou seja, restou abolida a presunção de periculosidade, vedando-se a incidência da sanção penal em epígrafe na ausência de fato delituoso. Destarte, a periculosidade criminal, já abordada, e a realização de um fato ilícito-típico penal passam a constituir os pressupostos da medida de segurança no ordenamento jurídico brasileiro.

Desse modo, por periculosidade se passa a entender o estado subjetivo mais ou menos duradouro de antisociabilidade, ou seja, um juízo de probabilidade tendo por base a conduta antisocial e a anomalia psíquica do agente, conforme Cezar Roberto Bitencourt (2000, p. 641), vale dizer, periculosidade real constatada por perícia, não presumida..

A reforma de 1984 também deu nova redação aos artigos 96 e 97 do Código, dispondo acerca das espécies de medida de segurança. A respeito do assunto, pontua Eduardo Reale Ferrari (2001, p. 40):

Com a finalidade de simplificar os tipos de medidas profiláticas, o Código Penal de 1984 enunciou apenas duas espécies de medidas de segurança, sendo uma de cunho privativo e a outra de cunho restritivo, denominando-as de internação em hospital de custódia e tratamento ambulatorial.

A internação psiquiátrica, também denominada medida de segurança detentiva, determina o cumprimento da medida de segurança nos chamados "hospitais de custódia e tratamento psiquiátrico (HCTPs)" ou, na ausência destes, em estabelecimentos adequados com características similares. Antes da reforma, os hospitais eram intitulados "manicômios judiciários"; a alteração na terminologia em nada modificou, porém, as condições dos estabelecimentos, que permaneceram com as mesmas características manicomiais (BITENCOURT, 2009, p. 746).

A segunda espécie é também denominada medida de segurança restritiva. Consiste na sujeição a tratamento ambulatorial, isto é, “imposição do acompanhamento médico 
psiquiátrico sem a obrigatoriedade de que o paciente permaneça recluso na instituição" (CARVALHO, 2013, p. 507). A referida espécie é prevista como uma providência excepcional, aplicável tão somente quando o fato for punível com detenção.

Assim sendo, constata-se que o critério para definição da espécie de medida de segurança é estabelecida conforme a gravidade do delito. Dispõe o artigo 97, supracitado: "Se o agente for inimputável, o juiz determinará sua internação (artigo 26). Se, todavia, o fato previsto como crime for punível com detenção, poderá o juiz submetê-lo a tratamento ambulatorial".

O raciocínio exposto consiste, no entanto, em um dos pontos mais criticados pela doutrina. Pontua Salo de Carvalho (2013, p. 508):

\begin{abstract}
A previsão em abstrato da forma reclusiva ou detentiva como critério único de definição da espécie de medida de segurança a ser cumprida não parece estar adequada ao postulado constitucional que determina ao julgador a individualização da sanção penal (medida de segurança). Note-se que, em relação às penas, a fixação do regime ou a possibilidade de substituição por pena restritiva de direitos independe da espécie de privação de liberdade prevista em lei. Assim, o tipo de regime (aberto, semiaberto ou fechado) e a espécie de sanção (privativa de liberdade, restritiva de direito ou multa) estarão subordinados aos critérios judiciais expostos motivadamente na sentença (individualização da pena). A definição das espécies de medida a partir de um critério abstrato parece, portanto, estar em oposição à estrutura principiológica (constitucional e legal) que orienta a aplicação das sanções.
\end{abstract}

Nesse sentido, Michele Cia (2011, p. 64) destaca por igual a urgente necessidade de revisão do artigo 97 do Código Penal. O dispositivo citado se baseia na finalidade preventivogeral, enquanto deveria prevalecer a finalidade preventivo-especial positiva, protegendo sempre as particularidades psicológicas dos inimputáveis.

Apresentadas as espécies da medida de segurança, outro ponto controverso na doutrina envolve os prazos mínimos e máximos da respectiva sanção.

O mesmo artigo 97 dispõe, em seu $\S 1^{\circ}$ : “A internação, ou tratamento ambulatorial, será por tempo indeterminado, perdurando enquanto não for averiguada, mediante perícia médica, a cessação de periculosidade. O prazo mínimo deverá ser de um a três anos”.

O dispositivo normativo disciplina o prazo mínimo da duração da medida de segurança e condiciona o prazo máximo à cessação da periculosidade do agente. $\mathrm{O}$ tema incita diversas críticas doutrinárias, dividindo estudiosos entre aqueles que defendem o disposto no texto legal e aqueles que alegam sua inconstitucionalidade. 
Em relação à obrigatoriedade de um prazo mínimo, Miguel Reale Júnior aduz que a questão pode ser solucionada com uma breve análise do artigo 176 da Lei de Execução Penal, o qual possibilita, a qualquer tempo, a realização de um exame que verifique possível cessação de periculosidade. Transcreve-se (2012, p. 500, grifo do autor):

\begin{abstract}
Quanto ao tempo mínimo, creio que o disposto na Lei de Execução Penal, em seu art. 176, bem resolve a questão, pois cumpre ao juiz adequar o tempo mínimo em proporção ao fato e à anomalia psíquica apresentada pelo réu, mas deixa-se uma importante válvula ao estabelecer: “... em qualquer tempo, ainda no decorrer do prazo mínimo de duração da medida de segurança, poderá o juiz da execução, diante de requerimento fundamentado do Ministério Público ou do interessado, seu procurador ou defensor ordenar o exame para que se verifique a cessação de periculosidade".
\end{abstract}

Por outro lado, no tocante ao prazo indeterminado, a crítica parte do pressuposto que, sendo a Constituição omissa em relação às medidas de segurança, reputa-se necessária uma interpretação ampla do termo "pena", abarcando a sanção penal como um todo (CARVALHO, 2013, p. 513). Assim, à medida de segurança seriam aplicados dispositivos como o artigo $5^{\circ}$, XLVII " $\mathrm{b}$ " da Carta Maior, que veda a perpetuidade da pena, e o artigo 75 do Código Penal, que limita o tempo de cumprimento da pena privativa de liberdade a 30 (trinta) anos. Nesse sentido é o entendimento do Supremo Tribunal Federal (BRASIL, 2011). In verbis:

EMENTA: PENAL. HABEAS CORPUS. RÉU INIMPUTÁVEL. MEDIDA DE SEGURANÇA. PRESCRIÇÃO. INOCORRÊNCIA. PERICULOSIDADE DO PACIENTE SUBSISTENTE. TRANSFERÊNCIA PARA HOSPITAL PSIQUIÁTRICO, NOS TERMOS DA LEI 10.261/2001. WRIT CONCEDIDO EM PARTE. I Esta Corte já firmou entendimento no sentido de que o prazo máximo de duração da medida de segurança é o previsto no art. 75 do CP, ou seja, trinta anos. $\mathrm{Na}$ espécie, entretanto, tal prazo não foi alcançado. II - Não há falar em extinção da punibilidade pela prescrição da medida de segurança uma vez que a internação do paciente interrompeu o curso do prazo prescricional (art. 117, V, do Código Penal). III - Laudo psicológico que reconheceu a permanência da periculosidade do paciente, embora atenuada, o que torna cabível, no caso, a imposição de medida terapêutica em hospital psiquiátrico próprio. IV - Ordem concedida em parte para determinar a transferência do paciente para hospital psiquiátrico que disponha de estrutura adequada ao seu tratamento, nos termos da Lei 10.261/2001, sob a supervisão do Ministério Público e do órgão judicial competente. (STF - HC: 107432 RS, Relator: Min. RICARDO LEWANDOWSKI, Data de Julgamento: 24/05/2011, Primeira Turma, Data de Publicação: DJe-110 DIVULG 08-06-2011 PUBLIC 09-06-2011) 
O Superior Tribunal de Justiça também se posicionou quanto ao assunto na súmula 527 (BRASIL, 2015). Vejamos: “O tempo de duração da medida de segurança não deve ultrapassar o limite máximo da pena abstratamente cominada ao delito praticado".

Do exposto, não obstante distinção nos posicionamentos dos referidos Tribunais, coadunam no sentido de que o prazo indeterminado previsto pelo artigo $97 \S 1^{\circ}$ do Código Penal é incompatível com o ordenamento jurídico pátrio, o que implica na necessidade de buscar novas alternativas aos inimputáveis que, embora não tenham sua periculosidade cessada, já cumpriram o tempo máximo previsto na lei, seja pela pena abstratamente cominada ou pelo prazo de 30 (trinta) anos.

\section{REFORMA PSIQUIÁTRICA E DESINTERNAÇÃO PROGRESSIVA: REFLEXOS NO SISTEMA PROCESSUAL PENAL}

Inobstante o cenário de isolamento e discriminação vislumbrado historicamente pelo indivíduo com transtornos mentais, sabe-se que a segunda metade do século XX traz consigo ideais de humanização e democratização do espaço hospitalar, os quais, com a Psiquiatria Democrática Italiana, acarretaram o rompimento dos paradigmas asilares e introduziram uma corrente de pensamento crítico sobre a instituição psiquiátrica.

Seguindo essa linha de pensamento, Franco Basaglia foi o precursor do que se chama de "processo de desmontagem do aparato manicomial", cuja essência seria a substituição do modelo asilar por espaços extra-hospitalares, buscando a extinção progressiva das instituições manicomiais.

No Brasil, o movimento chamado "Reforma Psiquiátrica" teve seus primeiros indícios em meados de 1970, materializando-se através do Projeto $\mathrm{n}^{\circ}$ 3.657, também conhecido como "Projeto de Lei Antimanicomial", apresentado ao Congresso Nacional em 1989. Nesse sentido (ALMEIDA JÚNIOR, 2013, p. 665):

\footnotetext{
O movimento de Reforma Psiquiátrica brasileira tem a sua própria história, alinhada inclusive ao contexto internacional, onde se buscava suplantar a violência do modelo asilar. A origem desse movimento, formado inicialmente por profissionais da área da saúde mental, remonta ao ano de 1970 e tem como um dos seus fundamentos a crítica ao saber e às instituições psiquiátricas clássicas, visando suas transformações. Os sofrimentos causados e as violações perpetradas contra os doentes levaram o movimento de Reforma Psiquiátrica a propor, diversamente dos postulados inerentes ao antigo modelo de atendimento, a desinstitucionalização, a desospitalização e a humanização na assistência aos mesmos.
} 
O referido projeto tramitou por mais de dez anos no Congresso Nacional, passando por diversas alterações. Em abril de 2001 a lei foi sancionada e promulgada sob o ${ }^{\circ} 10.216$, ficando popularmente conhecida como a "Lei da Reforma Psiquiátrica", que dispõe sobre a proteção e os direitos dos indivíduos com transtornos mentais, redirecionando o modelo assistencial em saúde mental.

Partindo para uma análise breve da lei, seu artigo $1^{\circ}$ do diploma legal dedica-se a assegurar os direitos e a proteção das pessoas acometidas de transtorno mental sem qualquer forma de discriminação quanto à raça, cor, sexo, orientação sexual, religião, opção política, nacionalidade, idade, família, recursos econômicos e ao grau de gravidade ou tempo de evolução de seu transtorno, ou qualquer outra. Tais direitos vêm exemplificados no artigo subsequente, a saber:

Art. $2^{\circ}$ Nos atendimentos em saúde mental, de qualquer natureza, a pessoa e seus familiares ou responsáveis serão formalmente cientificados dos direitos enumerados no parágrafo único deste artigo. Parágrafo único. São direitos da pessoa portadora de transtorno mental: I - ter acesso ao melhor tratamento do sistema de saúde, consentâneo às suas necessidades; II - ser tratada com humanidade e respeito e no interesse exclusivo de beneficiar sua saúde, visando alcançar sua recuperação pela inserção na família, no trabalho e na comunidade; III - ser protegida contra qualquer forma de abuso e exploração; IV - ter garantia de sigilo nas informações prestadas; $\mathrm{V}$ - ter direito à presença médica, em qualquer tempo, para esclarecer a necessidade ou não de sua hospitalização involuntária; VI - ter livre acesso aos meios de comunicação disponíveis; VII - receber o maior número de informações a respeito de sua doença e de seu tratamento; VIII - ser tratada em ambiente terapêutico pelos meios menos invasivos possíveis; IX - ser tratada, preferencialmente, em serviços comunitários de saúde mental.

$\mathrm{O}$ artigo $3^{\circ}$ ainda ressalta a responsabilidade do Estado no desenvolvimento da política de saúde mental, na assistência e na promoção de ações de saúde aos portadores de transtornos mentais, com a devida participação da sociedade e da família, a qual será prestada em estabelecimento de saúde mental, assim entendidas as instituições ou unidades que ofereçam assistência em saúde aos portadores de transtornos mentais.

Diante desse contexto, e considerando todo o exposto, questiona-se: "A Lei da Reforma Psiquiátrica aplica-se ao indivíduo com transtornos mentais submetidos à medida de segurança?"

Para alcançar uma resposta que atenda aos princípios norteadores do nosso ordenamento jurídico e responda aos anseios do Direito Penal, faz-se necessária uma breve análise da finalidade da medida de segurança e do instituto da desinternação progressiva. 


\subsection{A função preventiva da medida de segurança}

A par das inúmeras críticas quanto à problemática da finalidade retributiva da pena, cabe lembrar que o posicionamento majoritário é no sentido de que a pena restringe a liberdade do indivíduo, configurando-se como uma repreensão, mas também se preocupa com a utilidade e eficácia da medida, a fim de evitar a reiteração delituosa.

Por outro lado, a imposição da medida de segurança afasta o caráter retributivo da sanção penal, limitando-se ao seu aspecto preventivo.

Nesse ponto, "a existência de prevenção especial como finalidade precípua da medida de segurança é incontroversa" (CIA, 2011, p. 61), haja vista a busca pela reinserção social do inimputável e proteção da sociedade.

No tocante à prevenção geral, Eduardo Reale Ferrari, na mesma linha de Jorge Figueiredo Dias, posiciona-se no sentido de que o legislador quis alcançar finalidades preventivas gerais, sobretudo positivas. Dias (2001, p. 122) ressalta, ainda, que a finalidade de prevenção geral cumpre sua função autônoma, realçando exigências que são pressupostos da medida de segurança, como as da prática de um ilícito-típico grave e da proporcionalidade

Acerca do assunto, Michele Cia (2011, p. 64) pactua com o entendimento de que a medida de segurança possui finalidades preventivo-gerais de índole positiva, mas destaca sua posição secundária, uma vez que "a prevenção geral negativa não se inclui entre as expectativas próprias da medida de segurança, eis que o ato do inimputável não gera abalo na confiança comunitária com relação à vigência da norma".

\subsection{A desinternação progressiva como instrumento de reinserção social}

Expostas algumas considerações acerca da função preventiva da medida de segurança, resta evidente que a aplicação dessa sanção penal, mormente em sua modalidade detentiva, tem como propósito reinserir o inimputável e evitar a prática de novos delitos.

Considerando que o indivíduo submetido à medida de segurança foi diagnosticado com transtornos mentais e era, ao tempo da ação ou omissão, inteiramente incapaz de entender o caráter ilícito do fato ou de determinar-se de acordo com esse entendimento, evidente que a finalidade buscada pela sanção penal só será alcançada se a execução da 
medida envolver um tratamento terapêutico e psicológico com vias à readaptação social, o que não ocorrerá se o paciente for mantido sob isolamento.

Dessa forma, constata-se que a Reforma Psiquiátrica deve ser observada no âmbito da medida de segurança, promovendo, inclusive, uma aproximação entre comunidade e internos, a fim de incentivar o tratamento extra-hospitalar e a reinserção do indivíduo.

A Lei $n^{\circ} 10.216$ já havia revelado uma preocupação com a desospitalização e com o planejamento ressocializador. Dispõe o artigo $5^{\circ}$ do referido diploma legal:

\begin{abstract}
Art. 5o $\mathrm{O}$ paciente há longo tempo hospitalizado ou para o qual se caracterize situação de grave dependência institucional, decorrente de seu quadro clínico ou de ausência de suporte social, será objeto de política específica de alta planejada e reabilitação psicossocial assistida, sob responsabilidade da autoridade sanitária competente e supervisão de instância a ser definida pelo Poder Executivo, assegurada a continuidade do tratamento, quando necessário.
\end{abstract}

No que tange à medida de segurança, parte da doutrina e da jurisprudência ${ }^{3}$ já vem se posicionando favorável à desinternação progressiva, cuja aplicação prega um regime de execução progressivo e individualizado e tem fundamento no princípio da individualização da sanção penal. Nas lições de Eduardo Reale Ferrari (2001, p. 172 - 173):

\begin{abstract}
O inimputável ou o semi-imputável internado têm o direito à progressividade ao tratamento ambulatorial sob pena de afrontar-se à individualização na execução da sanção criminal, prevista constitucionalmente no art. $5^{\circ}$, inc. XLVI. A progressividade do internamento ao tratamento ambulatorial consiste numa garantia constitucional, inerente a qualquer cidadão, configurando-se sua inadmissibilidade um contra-senso às finalidades do tratamento.
\end{abstract}

Por outro lado, o instituto ainda não foi regulamentado pela legislação. Os Projetos de Lei $n^{\circ} 3.473 / 2000$ e $n^{\circ} 5.075 / 2001$ introduziram o tema, mas já se tornaram obsoletos e sequer foram apreciados de forma definitiva pelas casas legislativas.

A ausência de lei federal que discipline a desinternação progressiva acaba por obstar o fornecimento de mais recursos para sua execução. A atual estrutura dos hospitais de

\footnotetext{
${ }^{3}$ PENAL. RECURSO ORDINÁRIO EM HABEAS CORPUS. MEDIDA DE SEGURANÇA. CUMPRIMENTO DA MEDIDA EM PRAZO SUPERIOR AO DA PENA MÁXIMA COMINADA AO DELITO. PRESCRIÇÃO. INOCORRÊNCIA. INÍCIO DO CUMPRIMENTO. MARÇO INTERRUPTIVO. PERICULOSIDADE DO AGENTE. CONTINUIDADE. PRAZO MÁXIMO DA MEDIDA. 30 (TRINTA) ANOS. PRECEDENTES DO STF. DESINTERNAÇÃO PROGRESSIVA. ART. $5^{\circ}$ DA LEI 10.216/2001. APLICABILIDADE. ALTA PROGRESSIVA DA MEDIDA DE SEGURANÇA. PRAZO DE 6 (SEIS) MESES. RECURSO PROVIDO EM PARTE. [...]. 3. A desinternação progressiva é medida que se impõe, provendo-se em parte o recurso para o restabelecimento da decisão de primeiro grau, que aplicou o art. $5^{\circ}$ da Lei 10.216/2001, determinando-se ao Instituto Psiquiátrico Forense que apresente plano de desligamento, em 60 (sessenta) dias, para que as autoridades competentes procedam à "política específica de alta planejada e reabilitação psicossocial assistida" fora do âmbito do IPF. 4. Recurso provido em parte. (STF - RHC: 100383 AP, Relator: Min. LUIZ FUX, Data de Julgamento: 18/10/2011, Primeira Turma, Data de Publicação: DJe-210 DIVULG 03-11-2011)
} 
custódia, a carência de diagnósticos concretos e de um acompanhamento profissional adequado impede que esse instituto se consagre de forma efetiva, impossibilitando sua extensão aos demais hospitais de custódia e seu aperfeiçoamento naqueles que já o aplicam.

Além disso, é evidente que o investimento deve alcançar o Sistema da Saúde como um todo, uma vez que (CIA, 2011, p. 206)

[...] a eficácia da medida não depende apenas de investimentos em sua própria efetivação, mas deriva também da estruturação dos serviços públicos de uma maneira geral. Isso porque os ex-internos passarão, em sua maioria, a depender do Sistema Único de Saúde para prosseguir realizando seu tratamento, necessário para garantir sua estabilidade do ponto de vista médico e social, ou ainda, nos casos mais complexos, necessitarão serem abrigados por outras instituições públicas.

A desinternação progressiva pode ser, assim, um instrumento eficaz na efetivação dos princípios constitucionais e na inclusão social do sujeito inimputável, mas sua aplicação deve estar acompanhada de investimentos no Sistema de Saúde Mental e em políticas públicas de conscientização da comunidade, cujo amparo é essencial para eficácia da medida.

\section{CONCLUSÃO}

Na linha de institucionalização de um modelo que associe, como conceitos dinâmicos, Estado, pena e culpabilidade, estabeleceu-se, do desenvolvimento do texto, uma relação direta entre a análise da natureza e dos fins da pena com o conceito dogmático de culpabilidade adotado, hoje, pela legislação brasileira.

Buscando, assim - além de fugir de uma mera troca de etiquetas (pena versus medida de segurança) em especial diante do atual avanço das neurociências -, justificar e legitimar a delicada função que uma tal culpabilidade se propõe a realizar, qual seja, a de fundamentar o castigo estatal, concluiu-se, após discorrer-se sobre a problemática da inimputabiidade e da periculosidade e de seu tratamento normativo, dentro inclusive de um escorço evolutivohistórico, bem como das formas de sua apuração, ser incompatível a imposição indeterminada de medida de segurnça, posto contrariar principiologicamente o sistema constitucional vigente, já que em contraste com o postulado da dignidade humana.

Daí inserir-se, dentro da lógica de inspiração da reforma psiquiátrica, o instituto da desinternação progressiva, concluindo-se tratar-se de mecanismo eficaz na tutela não só deste 
postulado formal, mas sobretudo compondo o enredo de uma tendência inclusiva no viés dos procedimentos que garantem o Estado Democrático de Direito.

\section{REFERÊNCIAS}

ALMEIDA JÚNIOR, João Cauby. Arenas de produção de políticas públicas: a nova política nacional de saúde mental. Revista Direito GV. São Paulo. 2013. Disponível em: < http://direitosp.fgv.br/sites/direitosp.fgv.br/files/artigo-Edicao-revista/14-rev18_659-680__joao_cauby_de_almeida_junior.pdf> Acesso em 12 jun de 2015.

BITENCOURT, Cezar Roberto. Tratado de direito penal, volume 1: parte geral - 14. Ed São Paulo : Saraiva, 2009.

BRASIL, República do. Decreto $n^{\circ} 1.132$, de 22 de dezembro de 1903. Disponível em < http://www2.camara.leg.br/legin/fed/decret/1900-1909/decreto-1132-22-dezembro-1903585004-publicacaooriginal-107902-pl.html> Acesso em 21 jun. 2015.

BRASIL. Superior Tribunal de Justiça. Súmula 527, D.J 13/05/2015. Disponível em: < http://www.stj.jus.br/SCON/sumulas/toc.jsp?livre=\%22dura\%E7\%E3o+da+medida+de+segur an\%E7a\%22\&\&b=SUMU\&thesaurus=JURIDICO\&p=true > Acesso em 20 set. 2016.

BRASIL. Supremo Tribunal Federal. HABEAS CORPUS : HC 107432 RS. D.J. 24/05/2011. Disponível em < http://www.stf.jus.br/portal/jurisprudencia/listarJurisprudencia.asp?s1=\%28HABEAS+CORP $\mathrm{US}+\% 3 \mathrm{~A}+\mathrm{HC}+107432+\mathrm{RS} \% 29 \&$ base=baseAcordaos\&url=http://tinyurl.com/h6nxtam > Acesso em: 16 set. 2016.

BRASIL. Supremo Tribunal Federal. RHC: 100383 AP. D.J.: 18/10/2011. Disponível em: < http://www.stf.jus.br/portal/jurisprudencia/listarJurisprudencia.asp?s1=\%28RHC\%3A+10038 3+AP\%29\&base=baseAcordaos\&url=http://tinyurl.com/jk8v9um > Acesso em 22 set. 2016.

CARDOSO, Danilo Almeida; PINHEIRO, Jorge Augusto de Medeiros. Medidas de segurança: ressocialização e dignidade da pessoa humana - Curitiba: Juruá, 2012.

CARVALHO, Salo de. Penas de medidas de segurança no direito penal brasileiro: fundamentos e aplicação judicial - São Paulo: Saraiva, 2013.

CIA, Michele. Medidas de segurança no Direito Penal Brasileiro: a desinternação progressiva sob uma perspectiva político-criminal. São Paulo. Editora Unesp, 2011.

DIAS, Jorge de Figueiredo. Temas básicos da doutrina penal. Coimbra Editora. 2001

DINIZ. A custódia e o tratamento psiquiátrico no Brasil: Censo 2011. Brasília : LetrasLivres : Editora Universidade de Brasília, 2013. 
FERRARI, Eduardo Reale. Medidas de segurança e direito penal no estado democrático de direito - São Paulo: Editora Revista dos Tribunais, 2001.

FOUCAULT, Michel. A história da loucura. São Paulo : Perspectiva, 1972.

GRECO FILHO, Vicente. Manual de processo penal $-8^{\mathrm{a}}$ ed. rev., atual. e ampl. com a colaboração de João Daniel Rassi - São Paulo : Saraiva, 2010.

GOFFMAN, Erving. Manicômios, Prisões e Conventos. Tradução de Dante Moreira Leite. $7^{\mathrm{a}}$ edição. São Paulo: Editora Perspectiva, 2001.

MIRABETE, Julio Fabrini; FABRINI, Renato N. Código Penal interpretado. $8^{\text {a }}$ ed. São Paulo: Atlas, 2012.

NUCCI, Guilherme de Souza. Manual de direito penal: parte geral: parte especial - 7. Ed. Rev., atual. e ampl. - São Paulo : Editora Revista dos Tribunais, 2011.

OLIVEIRA, Eugênio Pacelli de. Curso de processo penal - $19^{\mathrm{a}}$ ed. rev. e atual. - São Paulo : Atlas, 2015.

PRADO, Luiz Regis. Curso de direito penal brasileiro, volume 1: parte geral, arts. $1^{\circ}$ a $120-$ 11 ed. rev. atual. e ampl. - São Paulo: Editora Revista dos Tribunais, 2011.

PONTE, Antonio Carlos da. Inimputabilidade e processo penal - 3. ed. - São Paulo : Saraiva, 2012.

REALE JÚNIOR, Miguel. Instituições de direito penal - Rio de Janeiro. Forense, 2012.

TABORDA, José G. V.; ABDALLA-FILHO, Elias; CHALUB Miguel. Psiquiatria forense $2^{\mathrm{a}}$ ed. porto Alegre : Artmed, 2012.

ZAFFARONI, Eugenio Raúl; PIERANGELI, José Henrique. Manual de direito penal brasileiro : volume 1 : parte geral. $9^{\mathrm{a}}$ ed. rev. e atual. - São Paulo: Editora Revista dos Tribunais. 2011. 